Preprints of the

Max Planck Institute for

Research on Collective Goods

Bonn 2016/1

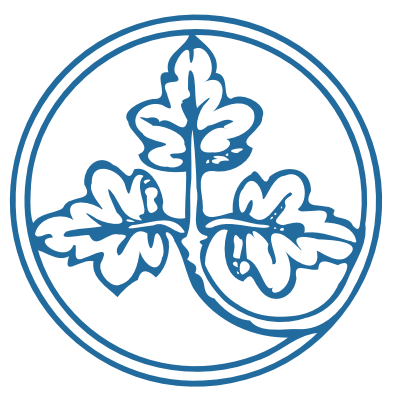

Mass Media, Instrumental Information, and Electoral Accountability

Christian Bruns

Oliver Himmler

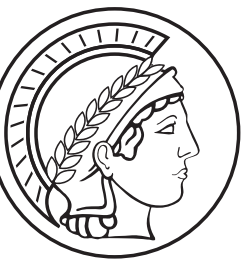




\section{Mass Media, Instrumental Information, and Electoral Accountability}

Christian Bruns / Oliver Himmler

January 2016 


\title{
Mass Media, Instrumental Information, and Electoral Accountability
}

\author{
Christian Bruns* \\ University of Goettingen
}

\author{
Oliver Himmler** \\ MPI Bonn
}

January 7, 2016

\begin{abstract}
Journalism is widely believed to be crucial for holding elected officials accountable. At the same time economic theory has a hard time providing an instrumental explanation for the existence of "accountability journalism". According to the common Downsian reasoning, rational voters should not be willing to pay for information out of purely instrumental motives because the individual probabilities of casting the decisive vote are typically very low. We show that this rationale does not apply when a group of voters shares a common goal such as accountability and information is delivered via mass media. In contrast to the pessimistic Downsian view, rational voters can have a considerable willingness to pay for the provision of instrumental information in these scenarios. Our model thus reconciles the rational voter approach with the common perception of journalism as a watchdog that holds elected officials accountable.
\end{abstract}

JEL-Codes: D72, D83, H41

Keywords: accountability, elections, information, media

\footnotetext{
*University of Goettingen, Platz der Goettinger Sieben 3, D-37073 Goettingen, Germany. email: cbruns@gwdg.de

** Max Planck Institute for Research on Collective Goods, Kurt-Schumacher-Strasse 10, 53113 Bonn,

Germany. email: himmler@coll.mpg.de

We thank the editor Kai Konrad and three anonymous referees for their helpful comments. We further thank Emre Aytimur, Lars Ehlers, Christoph Engel, Alia Gizatulina, Laszlo Goerke, Dominik Grafenhofer, Ioanna Grypari, Martin Hellwig, Svenja Hippel, Steffen Huck, Cesar Martinelli, Johannes Meya, Panu Poutvaara, Robert Schwager, Andreas Wagener as well as seminar participants at the Workshop on Economics in Tuebingen, the 2nd World Congress of the Public Choice Societies in Miami, the WZB, the IIPF Congress in Dresden, the 6th CESifo Workshop on Political Economy, the 12th Journées Louis-André Gérard-Varet, the APET Meeting in Lisbon, the Annual Meeting of the Verein fuer Socialpolitik in Duesseldorf, the Colloquium on Economics at the IAAEU and the Econ Workshop at the Max Planck Institute for Research on Collective Goods for helpful comments and suggestions.
} 


\section{Introduction}

Mass media offer a diverse bundle of content. Most of this content serves to facilitate private decisionmaking or provides entertainment value - think of business and stock market news, local sports results, the weather forecast, obituaries, announcements for events, or gossip about celebrities. Apart from this type of content, the media can also offer information which helps citizens hold politicians accountable. The view that the press as the "fourth estate" (Carlyle [1841] 1993) provides such information and helps keep the interests of politicians aligned with those of the electorate reaches back at least to Thomas Jefferson (1787):

"[...] were it left to me to decide whether we should have a government without newspapers, or newspapers without a government, I should not hesitate a moment to prefer the latter." because "once they [the people] become inattentive to the public affairs, you and I, and Congress, and Assemblies, judges and governors shall all become wolves" (Thomas Jefferson to Edward Carrington, 1787. Papers 11:48-49).

This idea is quite alive today. In 2013 more than two thirds of surveyed Americans said that "press criticism of political leaders keeps them from doing things that should not be done" (Pew Research Center, 2013). Accordingly, journalism which gathers and distributes such information is often referred to as "accountability journalism" (Bowles et al., 2013).

Extensive empirical evidence supports the idea that media coverage promotes accountability: There is convincing research which shows that the media do report on elected officials, that these reports lead to better informed voters, and as a consequence to increased accountability of politicians (see, for example, Snyder and Strömberg, 2010; Besley and Burgess, 2002; Ashworth, 2012). This evidence fits the popular narrative of investigative journalism acting as a watchdog mandated by the public to hold elected officials accountable (Hamilton, 2009; McChesney and Nichols, 2011; Waldman, 2011). Economic theory, however, has been at odds with the watchdog idea, which is based on the instrumental notion that voters demand information explicitly because it helps establish electoral accountability and then journalists produce this information.

This widely accepted account of media activity is not compatible with standard economic theory because of the "rational ignorance" paradigm (Downs, 1957): As a single vote is pivotal with only a very small probability in most elections, rational voters will not pay for information and thus there is no instrumental demand for information. It will therefore not be profitable for media outlets to include it in the bundle they provide, and they will have no incentive to engage in the monitoring of elected officials on behalf of the voters.

We show that there is, in fact, a rational explanation for instrumental demand for information. Consider a situation where voters use the past performance of an incumbent to evaluate whether or not to reelect him. It is well-known in the literature that the incumbent works harder whenever better 
monitoring of his performance allows for a more informed electoral decision (see Persson and Tabellini, 2002; Alesina and Tabellini, 2007, for example). It is therefore crucial for the incumbent's incentives whether a well-informed or an ignorant voter decides the election.

Assume that there are many voters who agree that more accountability is better, i.e. accountability is a valence issue. If this group of voters shares the same information, then each person in the group considers a situation where one of the fellow voters in the group decides the election to be equally desirable as a situation where the person itself is decisive. A key characteristic of a mass medium is that all its consumers are confronted with identical content, making it an effective technology to increase common knowledge among voters. When a voter determines his willingness to pay for higher reporting quality, he will take into account all scenarios in which he will benefit from the higher quality. Importantly, this includes not only the unlikely event where the voter himself is pivotal but also all situations where the election is decided by any other voter in the group who also observes the higher quality media coverage.

The result is striking: in the presence of mass media it is not a voter's low individual pivot probability that drives his willingness to pay for the provision of information. What matters is the typically much higher probability that the group of informed voters decides the election. This can translate into a substantial willingness to pay for instrumental information. When voters are willing to pay for this type of content the media will produce accountability information and add it to the bundle of content it provides.

We use a political agency model of the career concern type (Persson and Tabellini, 2002) to derive this motive due to which voters are willing to pay for higher overall levels of information in the electorate. The analysis reveals that when voters act according to this motive, the provision of accountability information can be understood as the private provision of a public good via profit-maximizing media platforms.

In our model, a commercial media outlet provides information if voters are willing to pay for it. One good example of where our analysis can apply are newspapers. Most newspapers either generate revenues by charging a (subscription) price and/or selling readers' attention to advertisers (Vogel, 2010; Shapiro and Varian, 2013; Baron, 2006; Gentzkow, 2014); recently, in the case of non-profits they also solicit donations directly from consumers. This implies that the production of news depends on the consumers' willingness to pay directly for content or their willingness to pay by accepting disruptive advertising. At the same time information provision by newspapers is a relevant scenario because they play a very important part in producing original reporting (Downie and Kaiser 2007, Pew Research Center 2010). In principle, our analysis can also apply to other types of commercial media outlets such as TV or radio, as long as they rely on a business model akin to what we have just described. The analysis does not apply to news organizations which also provide original accountability reporting but rely on a different business model, e.g. public broadcasters such as the BBC are often important providers of political reporting but are typically financed via mandatory fees or government grants. 
The applicability of our model also depends on the electoral circumstances. Accountability usually is a valence issue which most voters care about and thus the model applies in principle to elections on all levels of government - as long as the election is not completely dominated by ideological or partisan leanings of voters. Even so, the model is a particularly good fit for local and regional elections because in such settings ideology is typically not a big factor, whereas it might be in national elections. Local jurisdictions in the United States, for instance, are thought to be "managerial democracies" where "the politics of local governments are rarely fought along ideological lines", but rather the performance of incumbents is the primary interest (Oliver et al., 2012). At the same time these jurisdictions provide a wide array of services and their tax revenues almost match those of the federal government, so the accountability of incumbents is an important issue. That the media report information which plays a crucial role for establishing accountability at the local level is indeed backed by broad anecdotal and empirical evidence (Revelli, 2008; Snyder and Strömberg, 2010; Waldman, 2011; Prat and Strömberg, 2013), and our model supplies one plausible theoretical underpinning for this observation.

We believe that our model can provide insights for the recent discussion about the future of accountability journalism, which asks whether changes in the media landscape will see this form of reporting decline (Downie and Schudson, 2009; Waldman, 2011). First, the new instrumental angle on information provision can be a valuable tool, because it adds to our understanding of the phenomenon of media driven accountability. Second, the structural similarity of our mechanism to the literature on the private provision of public goods suggests that further insights from this literature can be of service when we try to understand how the media can help establish accountability.

To put our instrumental explanation for accountability journalism into perspective, we have to keep in mind that journalists also produce information which people demand because they find it entertaining or because it helps them to improve private decisions (Aidt, 2000; Gentzkow and Shapiro, 2006; Prat and Strömberg, 2013). The specific types of information which are produced to meet these demands can be independent of accountability information, but they can also overlap with it. In the latter case, knowledge which voters acquire for non-instrumental reasons can help them evaluate politicians and policies. Citizens can also be willing to acquire costly accountability information out of a sense of civic duty (Feddersen and Sandroni, 2006). Ultimately, it will depend on the specific context which motive (or combination of motives) on the demand side best describes the provision of accountability information.

Instrumental motives are common in the literature on endogenous information and voting (for a concise survey see Oliveros 2013). In contrast to our approach, the papers in this branch of the literature usually follow the Downsian perspective where rational voters base their demand for information on the likelihood of being pivotal (e.g. Martinelli 2006). Further, these papers analyze to which extent voters pay attention to exogenously given sources of information, whereas our model explains the incentives of the media to produce information in the first place.

In contrast to this literature, the papers by Strömberg $(2001,2004 a)$ are not concerned with 
the quality of collective decisions but with the question of how the incentives of commercial media influence public policies. In Strömberg's models, voters acquire information because they can better privately adapt to future policies if they are informed (see above). His earlier paper augments various political economy models by integrating a basic media market and also provides a section that alludes to accountability. Strömberg (2004a) analyzes the effects of media coverage, but in contrast to our paper the focus is on redistributive policies. On a general level our paper is different because we consider instrumental motives to pay for information rather than the private by-product explanation. But there is another important dimension of distinction: Strömberg's analysis explains how office seeking politicians allocate given resources across voter groups, whereas our model can explain how efficiently politicians use given resources once they actually are in office. Larcinese (2007) adapts the model in Strömberg (2004a) by considering demand for information which is driven by individual pivot probabilities. However, in his model newspapers do not undertake costly investigations but are perfectly informed by assumption. Further, in contrast to our paper he does not study effects on accountability.

Our paper also adds to the research on the political economy of mass media on a more general level. In addition to the branches we have just discussed above, this literature includes topics such as ideological media bias (Mullainathan and Shleifer, 2005; Gentzkow and Shapiro, 2006; Bernhardt et al., 2008; Gentzkow et al., 2014), pandering (Maskin and Tirole 2004) or media capture (Besley and Prat, 2006). Our analysis abstracts from these aspects. Although methodologically different, our paper is also similar in spirit to the empirical research on the political economy of mass media: Strömberg (2004b) shows that the mass media provide more political information to certain population groups, which then receive favorable policies. Empirical evidence that the mass media can affect accountability and the performance of government officials is provided by Besley and Burgess (2002), Reinikka and Svensson (2005), Shi and Svensson (2006), Svaleryd and Vlachos (2009), Snyder and Strömberg (2010), Bruns and Himmler (2011), and Drago et al. (2014).

We proceed by presenting the model in section 2 and the equilibrium analysis in section 3 . We discuss assumptions and the robustness of our main result in section 4 . Section 5 concludes.

\section{The model}

\subsection{Sketch of the model and description of publishing technology}

The analysis builds on a standard political agency model of the career concern type with two periods. Consider a city with $\mathrm{N}$ voters who receive utility from public goods. In period 1, there is an incumbent mayor (I) whose performance $g$ influences the level of public goods. At the end of period 1 the voters can either elect the incumbent or a challenger $(\mathrm{C})$. The winner influences public good provision in period 2 . 
Further, there is a profit-maximizing newspaper ${ }^{1}$ which provides the voters with a diverse bundle of content. Our analysis starts with the hypothetical situation where the newspaper does not provide information about the incumbent. We assume (and do not model explicitly) that all voters already read this newspaper in order to be entertained or to obtain information which helps them improve private decisions. The newspaper can now decide whether or not to investigate and add accountability reporting.

If the newspaper adds accountability reporting to the bundle of content, a reader who consumes the newspaper over the period of an electoral term will learn something about the incumbent's performance. This may sound natural, but due to its instrumental nature, voters do not receive any direct private benefit from reading the accountability information and therefore do not actively seek it out. However, the media can publish information in a way that makes sure it will not go unnoticed, for example by putting an article on the front page or by mixing accountability information with other types of information (when readers want to learn whether a newly built road will be opened soon the newspaper can also let them know who was responsible for building it, and whether it was built without financial waste). ${ }^{2}$ Readers can thus be made aware of accountability content although they read the newspaper for other reasons.

This is an effective technology of making readers learn about something because media content is an experience good, where consumers do not know the specific content of a newspaper copy or a newscast before they have consumed it (Shapiro and Varian, 2013). Consumers either have to browse and scan the bundle of content in order to find what they are interested in, or in the case of TV and radio they have to wait and see whether there will be anything interesting. In the process they come across information they were not looking for. This means, for example, by designing newspaper pages and articles in a specific way, certain information can be brought to the attention of consumers.

Empirical evidence shows that indeed even those consumers of mass media who initially do not intend to process information on a certain topic will learn something about it. This phenomenon of processing information without effort or intent is often referred to as 'passive learning' or 'incidental learning' (Krugman and Hartley, 1970; Zukin and Snyder, 1984; Graber, 1988; Culbertson and Stempel, 1986; Tewksbury et al., 2001; Schönbach et al., 2005; de Waal and Schoenbach, 2008).

We will now show that a voter wants the newspaper to disseminate accountability information and that the newspaper finds it lucrative to add accountability reporting to the bundle of content it offers.

\footnotetext{
${ }^{1}$ Our analysis can also apply to other types of commercial media outlets such as TV or radio.

${ }^{2}$ Basically, a media outlet can make it more costly to avoid information than to process it.
} 


\subsection{The electoral game}

In period $t \in\{1,2\}$ the performance of an incumbent is

$$
g_{t}^{j}=e_{t}^{j}+\theta^{j} \quad \text { with } j \in\{I, C\}
$$

where $e_{t}^{j} \geq 0$ denotes the respective incumbent's effort and $\theta^{j}$ his competence. Incumbent and voters share the common prior belief that competence is a normal random variable with mean $\bar{\theta}$ and precision $\tau_{\theta}$.

Effort is costly: if the incumbent spends more money or time on public good production, fewer resources are left that can be channeled to unproductive activities which are pleasant for the incumbent. The function $\gamma(e)$ measures these foregone pleasures due to exerting effort. ${ }^{3}$ Our results apply to functions $\gamma(e)$ that are strictly convex with $\gamma(0)=0, \gamma^{\prime}(e)>0, \gamma(e)^{\prime \prime}>0$ and $\lim _{e \rightarrow 0} \gamma^{\prime}(e)=0$. For ease of exposition, however, we will use the specific function $\gamma(e)=\frac{1}{2} e^{2}$ in the analysis.

The game ends after period 2, and so neither the incumbent nor the challenger will exert any effort in period 2. This allows us to drop the time subscript regarding effort so that $e$ denotes effort in period 1 from now on. The incumbent then chooses effort in period 1 in order to maximize

$$
\rho(e) \cdot R-\frac{1}{2} e^{2}
$$

where $\rho(e)$ denotes the probability of re-election and $R>0$ an exogenously given ego rent of being in office. So the incumbent weighs the cost of effort in period 1 against the expected rent in period 2 .

Each voter's preferences regarding the incumbent's performance are described by the utility function $u_{t}=g_{t}$. We let $v_{i} \in\{I, C, \emptyset\}$ represent voter i's voting decision, where $\emptyset$ means abstention. Throughout the analysis we assume that voting is costless.

As performance in period 2 is determined solely by the competence of the office holder $\left(g_{2}^{I}=\theta^{I}\right.$ or $g_{2}^{C}=\theta^{C}$ ), voters want to elect the more competent candidate. Voters and incumbent both know that the voters can extract information about the incumbent's competence $\left(\theta^{I}\right)$ from his performance in period 1. Thus, by exerting effort the incumbent can try to manipulate the voters' perception of his talent in order to influence the probability of being reelected $\rho(e)$.

\subsection{Newspaper}

We assume that voters cannot observe the incumbent's performance $(g)$ directly. This can be the case when the incumbent's performance has long-term consequences so that voters do not observe their utility before the election, as in Besley and Prat (2006).

\footnotetext{
${ }^{3}$ Alesina and Tabellini (2007) and Gehlbach (2007) show that our 'effort story' can easily be transformed into a rent-seeking model. The basic idea in both variants is that politicians can influence policy outcomes via a costly action.
} 
Alternatively, this premise can be interpreted as a shortcut to describe that voters on their own cannot precisely assess the incumbent's performance. Consider that public good provision usually does not depend on one politician's performance but is determined in a complex political and economic environment. To name a few factors, other politicians, bureaucrats or the state of the economy also influence the level of public goods. What the voters can observe before the election is the utility which results from total public good provision, but they cannot single out the incumbent's specific contribution. There is also no incentive for a voter to improve his knowledge by privately investigating the incumbent's performance. This would be prohibitively costly, given the low significance of a single vote. For now, we assume that voters do not receive a costless signal about the incumbent at all, but we will later discuss the implications of allowing for such a crude private signal.

Private investigations are too costly, but the technology of mass media provides a natural way of circumventing this problem. This is because accountability is a valence issue and all voters are interested in a well-informed electoral decision. They can therefore delegate information provision to a specialized expert - the newspaper. It can then undertake investigations and disseminate the resulting information simultaneously to many voters. In more technical terms, the newspaper can improve the quality of common knowledge among its readers. For the analysis it is important to realize that accountability reporting differs from most other media content such as entertainment in a crucial way: No one can be excluded from enjoying the better policy outcomes which result from accountability reporting. Thus, the provision of accountability reporting has to be modeled as the market provision of a pure public good.

Market reasoning implies that a newspaper will only offer content which is costly to produce if it creates sufficient additional revenues in return. There are different business models upon which a newspaper can rely, but they have in common that an increase in revenues results either directly or indirectly from the voters incurring a cost. Readers can be willing to pay indirectly by accepting advertising, or they can directly spend money and pay a (subscription) price. Traditionally, print has relied heavily on advertising, which as recently as 2010 accounted for roughly $75 \%$ of revenues (Vogel, 2010). This share is continuously declining, and circulation revenues are becoming more important. ${ }^{4}$ Recently, a third business model which also relies on direct revenue streams from consumers has gained traction: an increasing number of non-profit newspapers offer the opportunity to directly donate money towards reporting (Pew Research Center, 2013). ${ }^{5}$ The basic mechanism of our model is indifferent to which one of these business models (or a combination thereof) the newspaper employs. For ease

\footnotetext{
${ }^{4}$ Pew Research's State of the News Media (2015) reports that in 2014 seven of the largest publicly traded newspaper companies on average derived $57 \%$ of their income from advertising and $36 \%$ from circulation. The advertising share has been declining lately, mostly because of dramatically lower ad revenue: the Columbia Journalism Review reports that the ad-to-subscription ratio was down from 4.6-to-1 in 2005 to 1.9-to-1 in 2012 (see http://www.cjr.org/the audit/newspaper_subscription_revenue.php). On the internet, direct payments play a big role. Paywalls have become accepted in the recent past and for example the New York Times makes more money on the web from paid subscriptions than from digital advertising (http://www.cjr.org/the_audit/the_stand-alone_new_york_times.php).

${ }^{5}$ Many non-profits explicitly see their purpose in carrying out a watchdog role. Pew Research Center (2013) counts 172 non-profit news organizations established from 1987 to 2012, most of which are digital ventures. They lean towards covering state or metro level affairs, but there are also sites like ProPublica which focus on the national level.
} 
of exposition and due to the increasing significance of direct payments, we follow Baron (2006) and assume that the newspaper directly charges a monetary price for content. ${ }^{6}$

Because no one can be excluded from the benefits of accountability investigations, voters have incentives to free ride on the content which has already been paid for by fellow voters. This implies that an individual determines his willingness to pay according to the following rationale: Voter $i$ considers the reporting quality which he expects to result from the payments of fellow voters and he is only willing to pay the newspaper if his payment increases the quality of the accountability information.

We thus model the interaction between the newspaper and the voters as follows. The newspaper offers a package $(p, c)$, where $p$ denotes the price the newspaper charges for an increase of investigative activities by $c$ units. Let $D$ denote the number of voters who pay the newspaper for investigations. Then, the newspaper engages in investigations of extent $x=D \cdot c$ and we shall call $x$ the quality of investigations which results from the package offered by the newspaper and the voters' decisions of whether or not to pay.

The newspaper's investigations result in a signal

$$
s=g_{1}+\varepsilon
$$

where $\varepsilon \sim N(0,1 / x)$ is independent of $g_{1} \cdot{ }^{7}$ Thus, higher quality implies a more precise observation of the incumbent's performance. Quality can be chosen, for example, by hiring journalists of the needed talent or by assigning given staff to work on accountability investigations for the needed amount of time.

The main point of the paper can be made in the most straightforward manner if we focus on a situation where the newspaper can with certainty influence the level of common knowledge among its readers and where the votes of these readers are decisive for the collective decision. This is why we assume that all voters receive the signal. In reality, there might be some media consumers who fail to notice the accountability reporting while other people who do not consume the medium learn about the incumbent due to communication with informed newspaper consumers. Mondak (1995), for example, shows that information published by media can spill over via social interactions. Allowing for these possibilities does not change the main result of our model, and in section 4 we discuss the implications of introducing voters who do not consume the newspaper.

\footnotetext{
${ }^{6}$ Depending on the business model, the conversion of the voters' resources attention or money into content can differ, but this only results in variations of the mechanism presented in this model.

${ }^{7}$ In principle, the newspaper could produce a signal about an incumbent's performance in both time periods. However, as the game ends after period 2 there won't be any benefit from a signal in period 2 and thus we exclude it from the analysis for ease of exposition.
} 
The newspaper chooses $(p, c)$ in order to maximize the profit ${ }^{8}$

$$
\Pi(p, c)=D(p, c) \cdot(p-k \cdot c)
$$

where $k$ is the cost of producing one unit of $c$.

Each voter has to make two decisions: (i) the voting decision $v_{i}$ and (ii) the decision whether or not to accept the newspaper's offer. Let $\lambda_{i} \in\{0,1\}$ denote voter $i$ 's decision regarding the newspaper's offer, where $\lambda_{i}=1$ if the voter accepts and $\lambda_{i}=0$ if he does not accept. Each voter makes his decisions so as to maximize his inter-temporal utility ${ }^{9}$

$$
u_{i}=g_{1}\left(\lambda_{i}, v_{i} ; \lambda_{-i}, v_{-i}\right)+g_{2}\left(\lambda_{i}, v_{i} ; \lambda_{-i}, v_{-i}\right)-\lambda_{i} \cdot p
$$

where $\lambda_{-i}$ and $v_{-i}$ represent the respective decisions of the other voters. Having described the decision problems of the players, we summarize the game before turning to equilibrium analysis.

\subsection{Timing}

Period 1:

- Nature selects the competence of the incumbent $\theta^{I}$, which remains unknown to all players.

- The newspaper offers the package $(p, c)$ and then the voters decide whether or not to accept the offer.

- The incumbent observes the resulting reporting quality $x$ and chooses the effort level $e$. Then his performance $g=e+\theta^{I}$, which adds to the level of public goods, is realized.

- The newspaper investigates and sends the signal to the voters.

- The election takes place.

Period 2:

- The talent of the winner of the election determines performance in period 2.

\section{Equilibrium}

\subsection{Voting}

As voters understand that neither of the two candidates will exert effort in period 2 they want to elect the candidate who appears to be more competent. A voter can extract information about the incumbent's competence from the signal and update his belief. We assume that voters are rational in the sense that they update their belief using Bayes' rule, given their expectation $\tilde{e}$ about the

\footnotetext{
${ }^{8}$ The analysis by Glazer (2014) suggests that non-profit newspapers basically behave just like for-profit newspapers which makes our results directly applicable to non-profits, too.

${ }^{9}$ There is no discounting.
} 
incumbent's effort. It follows (see, for example, DeGroot 1970 or Pratt et al. 1995) that a voter's posterior belief about the incumbent's competence is described by a normal distribution with mean

$$
E\left(\theta^{I} \mid s, x, \tilde{e}\right)=\frac{\tau_{\theta} \bar{\theta}+x \cdot(s-\tilde{e})}{\tau_{\theta}+x} \quad \text { and precision } \quad \tau=\tau_{\theta}+x
$$

Thus, for a realized value $s$ of the signal a reader prefers the incumbent if

$$
E\left[\theta^{I} \mid s, x, \tilde{e}\right]-\bar{\theta} \geq 0 \quad \Leftrightarrow \quad s \geq \tilde{e}+\bar{\theta}
$$

and the challenger otherwise. ${ }^{10}$ So all the newspaper needs to communicate to the voters is whether or not performance was above average.

In our simple setup, it is straightforward to see that for each voter it is a weakly dominant strategy to vote according to the signal. A single vote is relevant for the outcome of the election only if it is pivotal, which is the case in the following three events: (1) his preferred candidate leads by one vote, (2) the unwanted candidate leads by one vote or (3) there is a tie. Following the signal therefore increases the probability that the candidate who appears to be more talented wins, and it rules out making the mistake of voting against the opinion of a better informed voter. Let $v^{*}$ denote the outcome of the collective decision in equilibrium. We then have

Lemma 1. In equilibrium, the collective decision is

$$
v^{*}=\left\{\begin{array}{l}
I \quad \text { for } \quad s \geq \tilde{e}+\bar{\theta} \\
C \quad \text { for } \quad s<\tilde{e}+\bar{\theta}
\end{array}\right.
$$

Proof. See above.

Lemma 1 implies that the collective decision is based on the signal. This means that newspaper coverage is highly effective because none of the information the newspaper produces goes to waste (by not having any effect on the election). In section 4 we discuss the effectiveness of newspaper information in richer setups where voters can differ in their levels of knowledge or partisan preferences, as in Feddersen and Pesendorfer (1996).

\footnotetext{
${ }^{10}$ In the game between the incumbent and the voters, no out-of-equilibrium action of the incumbent can be observed because the distributions of the random variables $\theta^{I}$ and $\varepsilon$ have full support on the real line. From a voter's perspective, any signal he receives is consistent with his equilibrium belief, because he attributes the difference between a realization of the signal and his belief to realizations of the random variable $\theta^{I}+\varepsilon$ which can be every value on the real line.
} 


\subsection{Effort}

The incumbent understands that he will be reelected if his observed performance is above the expected performance of an average politician:

$$
s \geq \tilde{e}+\bar{\theta}
$$

From the incumbent's prior perspective, the signal is a normal random variable with mean $(e-\tilde{e})$ and precision $\frac{\tau_{\theta} \cdot x}{\tau_{\theta}+x}$ and thus the probability of reelection is

$$
\rho(e)=\operatorname{Pr}[s \geq \tilde{e}+\bar{\theta}]=1-\Phi\left[-(e-\tilde{e}) \sqrt{\frac{\tau_{\theta} \cdot x}{\tau_{\theta}+x}}\right],
$$

where $\Phi$ denotes the standard normal distribution function. Hence, maximizing $\rho(e) \cdot R-\frac{1}{2} e^{2}$ for given $\tilde{e}$ and then imposing rational expectations $(e=\tilde{e})$ yields

Lemma 2. In equilibrium, the incumbent's effort equals

$$
e^{*}=\frac{1}{\sqrt{2 \pi}} \cdot \sqrt{\frac{\tau_{\theta} \cdot x}{\tau_{\theta}+x}} \cdot R
$$

Proof. See above. ${ }^{11}$

It follows from Lemma 2 that higher information quality $(x)$ makes the incumbent work harder. In the next section, we will determine quality in equilibrium.

\subsection{Market provision of information}

\subsubsection{The value of information}

It follows from Lemma 1 that a voter's payment to the newspaper will improve the informational basis of the collective decision with certainty. Higher quality of information $x$ has two beneficial effects for voters. First, there is an incentive effect, because the incumbent's effort in period 1 increases in quality (see Lemma 2). Second, higher quality improves the selection of talented candidates into office.

Given the voting equilibrium $v^{*}$ and some quality $x$, from the prior perspective (before the newspaper

\footnotetext{
${ }^{11}$ The distribution function $\Phi$ is both concave and convex on part of its domain. We assume that $R$ lies below the upper bound $\frac{1}{\varphi(1)} \frac{\tau_{\theta}+x}{\tau_{\theta} x}$ which ensures that the incumbent's objective function is concave so that the first order condition is sufficient to characterize the optimal level of effort (see also Ashworth 2005).
} 
has sent the signal) the expected competence of an incumbent in period 2 is $E\left[E\left(\theta^{v^{*}} \mid s, x\right)\right]$ where

$$
E\left(\theta^{v^{*}} \mid s, x\right)= \begin{cases}E\left(\theta^{I} \mid s, x\right) & \text { for } s \geq e^{*}+\bar{\theta} \\ E\left(\theta^{C}\right)=\bar{\theta} & \text { for } s<e^{*}+\bar{\theta}\end{cases}
$$

Information is valuable regarding the selection problem because it reduces the risk of selecting the wrong (i.e., the less competent) candidate, and so the voter can expect a higher level of public goods in period 2.

The total value of information quality can be described by a well-behaved function. Assume that there is reporting of some quality $x>0$ that comes for free. Then, a voter's expected utility is

$$
u(x>0)=\underbrace{e_{1}(x)}_{\text {incentive effect }}+E\left(\theta^{I}\right)+\underbrace{E\left[E\left(\theta^{v^{*}} \mid s, x\right)\right]}_{\text {selection effect }} .
$$

In case that there is no signal at all $(x=0)$ a voter's expected utility is

$$
u(x=0)=2 \cdot \bar{\theta}
$$

The value of information that a voter attributes to information quality $x>0$ is the difference in utility between the two cases: $u(x>0)-u(x=0)$. We define the function

$$
f(x):=u(x>0)-u(x=0)
$$

and obtain

Lemma 3. The value a voter attributes to information quality $x$ is measured by the function

$$
f(x)=\varphi(0) \cdot\left(R+\frac{1}{\tau_{\theta}}\right) \cdot \sqrt{\frac{\tau_{\theta} \cdot x}{\tau_{\theta}+x}} .
$$

where $\varphi$ is the density function of the standard normal distribution. The function $f(x)$ is strictly increasing in $x$ and strictly concave with infinite slope at the origin.

Proof. See Appendix.

We have now determined the value of information quality for a voter, and so we can derive equilibrium quality in the next section. 


\subsubsection{Information provision in equilibrium}

In a symmetric equilibrium, voter $i$ accepts the newspaper's offer if

$$
f\left(c+c_{-i}\right)-f\left(c_{-i}\right) \geq p
$$

where $c_{-i}$ denotes the contributions of the other voters. The newspaper charges $p^{*}=f\left(c+c_{-i}\right)-f\left(c_{-i}\right)$ and chooses $c$ in order to maximize profit per reader

$$
\Pi_{i}(c)=f\left(c+c_{-i}\right)-f\left(c_{-i}\right)-k \cdot c .
$$

Equilibrium quality of reporting is then characterized by the first-order condition

$$
f^{\prime}\left(x^{*}\right)=k
$$

where $x^{*}=N \cdot c^{*}$. As $f^{\prime}(x)=\infty$ at the origin and $f^{\prime \prime}(x)<0$, there is a unique interior solution to equation (12) and we arrive at

Proposition 1. In equilibrium, the newspaper provides accountability reporting of quality $x^{*}>0$ which is characterized by $f^{\prime}\left(x^{*}\right)=k$.

Proof. See above.

The equilibrium quality of investigations is characterized by a situation where a voter's marginal willingness to pay, evaluated at the total amount of contributions, equals the cost of increasing quality by one unit. The technology of mass media makes a voter's payment for accountability reporting very effective in influencing the collective decision. Since the voter can benefit from the fact that the votes of fellow voters also become more informed, his willingness to pay is not diminished by the individual probability of being pivotal. Instead, it is determined by the much larger probability that one of the informed voters decides the election. Here this probability is one, of course, because all voters are informed in equilibrium.

In essence, the provision of accountability reporting can be likened to the standard problem of the private provision of a public good. In contrast to the standard approach, the profit-maximizing newspaper sets a take-it-or-leave-it offer $(p, c)$ for contributing to accountability reporting. Despite this difference, the resulting equilibrium quality is the same quality that would be realized in a symmetric equilibrium of a game where voters can freely choose their contribution at cost $k$ per unit. ${ }^{12}$

Notably, all voters are strictly better off in equilibrium. While the newspaper can extract the surplus that a voter creates with his own payment $\left.\left.\left(p=f\left[N c^{*}\right)\right]-f\left[(N-1) c^{*}\right)\right]\right)$ all voters enjoy the

\footnotetext{
${ }^{12}$ Bruns and Himmler (2014) show that this result holds when there are competing newspapers. See Besley and Ghatak (2007) for a similar result.
} 
benefit $\left.f\left[(N-1) c^{*}\right)\right]$ generated by the payments of fellow voters. Since the newspaper also makes a profit, all players benefit when the newspaper bundle contains accountability reporting.

\section{Discussion and robustness}

1) Heterogenous voters. Our mechanism builds on the insight that a voters' willingness to pay for information depends on the probability that the group of newspaper readers is decisive. This motive holds in more general settings than we have considered so far. Suppose there are voters who either do not observe the signal or do not understand it as well as other voters. If such an individual votes for one of the candidates he risks voting against a better informed voter, which would decrease the probability that the candidate favored by informed voters wins. Thus, given that the informed follow the signal, the best response of less informed voters is to abstain in order to maximize the probability that informed voters decide the election. This is a variant of the swing voter's curse (Feddersen and Pesendorfer, 1996). ${ }^{13}$

We could also introduce partisan voters, whose decision is solely determined by their party preference, as in Feddersen and Pesendorfer (1996). In this case, a contribution to reporting quality will result in a better informed collective decision if one of the (non-partisan) newspaper readers casts the decisive vote. The probability of this event can be smaller than one but will typically still be (much) larger than the very low probability that a single vote is decisive. With partisans the benefits from higher reporting quality can therefore be diluted, but a voter's willingness to pay remains substantially higher than in models that focus on individual pivot probabilities. ${ }^{14}$ Even if there are voters who do not vote strategically but simply vote sincerely, there is some probability that one of the newspaper readers decides the election and thus the principle of our mechanism holds.

2) Non-excludability of accountability information. It also follows from Proposition 1 that equilibrium quality is independent of the number of voters. This result derives from the fact that no voter can be excluded from the benefits of a better informed collective decision. As a consequence, voters can free ride on the contributions of fellow voters and the newspaper cannot realize scale effects because it can sell each unit of quality only once. So it is not surprising to find that the quality of investigations in equilibrium is lower than the optimum which solves

$$
N \cdot f^{\prime}(x)=k
$$

\footnotetext{
${ }^{13}$ In Feddersen and Pesendorfer (1996) there is an exogenous stochastic process that determines whether or not a voter is informed. The interested reader can find a formal proof of the swing voter's curse for the case of information provision by newspapers in Bruns (2013). Battaglini et al. (2010) show that subjects in a laboratory experiment behave in a way that is consistent with the swing voter's curse.

${ }^{14}$ It is well known in the literature that in a model with partisan voters, uninformed neutral voters will not always abstain, but can vote strategically for the candidate with less partisan support. This reduces the gap in votes between the two candidates which results from partisan votes. It is more likely that informed neutrals decide the election the smaller this gap is.
} 
The finding that information is underprovided echoes concerns of media experts that the market provides too little so-called 'hard news' as compared to 'soft news' (Gentzkow and Shapiro, 2008; Hamilton, forthcoming). From the fact that the newspaper can sell each unit of quality only once, it can be seen that the commercial appeal of accountability news tends to be lower when compared to content such as entertainment. If resources like news space are limited, accountability news can then be in danger of being crowded out by more lucrative content. ${ }^{15}$ The move in the industry towards the digital distribution of news is likely to loosen such resource constraints, so that all content which generates a profit can be published. ${ }^{16}$ Interestingly, this means that the current shift in technology can reduce the risk that accountability news are crowded out.

3) Warm glow. When considering the equilibrium quality of information it is important to note that our setup may be too pessimistic. It is widely believed that models which include a warm glow of contributing have high explanatory power for the private provision of public goods (Diamond and Vartiainen, 2012). Let $h(c)$ with $h^{\prime}>0$ and $h^{\prime \prime}<0$ denote the warm glow utility derived from a contribution. If we consider the standard additive case where a voter enjoys utility $h(c)+f\left(c+c_{-i}\right)$ from contributing, the quality of investigations in equilibrium is defined by

$$
h^{\prime}\left(x^{*} / N\right)+f^{\prime}\left(x^{*}\right)=k .
$$

Including warm glow thus implies (i) that reporting quality is higher than in the standard model and (ii) that reporting quality is increasing in the size of the electorate.

A model with warm glow also provides an interesting connection to group-based models of information acquisition (Feddersen and Sandroni, 2006; Piolatto and Schuett, 2015). This approach solves the problem of low pivot probabilities by assuming that voters receive a warm glow by fulfilling their civic duty derived from Kantian-style reasoning. Group-based models and our approach share the feature that a voter's willingness to pay depends on the relevance of a group of voters. However, we need not give up the assumption that voters are selfish in order to explain the provision of information.

4) Cost of receiving information. A necessary condition for our mechanism to work is that in equilibrium there are voters who receive the newspaper's message. So far, our result has been based on the assumption that voters receive the newspaper's message at no cost. Suppose there is a cost $\kappa>0$ of receiving and processing the message. Can introducing such a cost lead to an equilibrium where no voter receives the message anymore?

Given that other voters receive accountability information, a voter is still willing to pay for an improved electoral outcome, but because of the low probability that his vote is decisive, it is not important for him to receive the information himself. Thus, he may feel tempted to avoid processing

\footnotetext{
${ }^{15}$ We thank Cesar Martinelli for pointing us this problem.

${ }^{16}$ The New York Times' David Carr points to limited resources that shape decisions about content: "[...] We're built on scarcity in print. [...] You move that over to the web [...] We can make more of anything." (UT Austin 2012 Mary Alice Davis Distinguished Lecture).
} 
the message. This reasoning, however, does not imply that in equilibrium there is no voter who receives accountability information.

Remember that in reality accountability information is part of a bundle of newspaper content. We have argued above that it is hard for voters to avoid published accountability information given that they read the newspaper. Thus, for our mechanism to break down, it would be necessary that all voters stop reading the newspaper once the newspaper adds accountability content. This scenario does not seem very plausible for the following reasons.

It is important to note that readers usually differ in their valuations of the elements of the news content bundle, and so the newspaper cannot charge a price which extracts all surplus. It follows that voters enjoy a surplus from reading the paper, which they would forfeit if they quit reading. So the question boils down to whether the surplus is larger than the cost of processing the accountability information.

The cost $\kappa$ of processing the information will not be of substantial magnitude but rather a minor inconvenience. Remember that all the newspaper has to communicate is whether or not observed performance is above average $(s \geq \tilde{e}+\bar{\theta})$. The message can thus be highly condensed (as in Chan and Suen 2008), and communicated by the newspaper in appropriate headlines, pictures and describing words. Processing these elements requires so little effort - in fact it may be automatic (see our earlier argument on passive learning) - that it is very unlikely that all voters will give up reading the paper.

Because voters continue to read the newspaper, including accountability information in the bundle of content is an effective way of disseminating this information among voters. Then, a voter's payoff from having accountability content included is $\left.f\left[(N-1) c^{*}\right)\right]-\kappa$. As $\kappa$ is very small, the payoff will be positive. Thus, the voters do not only continue to read the newspaper despite the cost, but - because having accountability information published implies that fellow voters receive the message - they also explicitly want accountability content included.

Our model can also hold in the rather theoretical case where accountability information comes as a solitary (and maybe more easily avoidable) signal and not as part of a bundle of newspaper content. Analogous to models which study turnout when voting is costly (Palfrey and Rosenthal, 1983), there can be (mixed-strategy) equilibria where voters receive the signal as long as the cost of receiving the message is not prohibitively large.

5) Private signals. We have shown that voters pay the newspaper for increasing common knowledge about the incumbent. But will this result hold if each voter also receives a (free) private signal about the incumbent's performance?

The literature on the jury theorem has shown that crude private signals can be sufficient to ensure selecting the better candidate (e.g. Austen-Smith and Banks, 1996; Feddersen and Pesendorfer, 1997), even if a signal comes at a small cost (Martinelli, 2006). In addition, Aytimur and Bruns (2015) show that a large electorate where voters receive noisy private signals can hold incumbents accountable to 
the same extent as a social planner who can perfectly monitor performance. Crude private signals therefore can be sufficient to solve both the incentive and the selection problem. If voters expect these mechanisms to work, they will not be willing to pay for additional information that comes in the newspaper.

But it is crucial for these optimistic results that the private signals are sufficiently independent across voters. For example, Aytimur and Bruns (2015) show that if voters' private signals $s_{i}=g+\eta+\varepsilon_{i}$ have both common (correlated) noise $\eta$ and individual (independent) noise $\varepsilon_{i}$, then the law of large numbers will eliminate the adverse effect of individual noise, but the extent of collective noise will still crucially affect an incumbent's incentives. ${ }^{17}$ Reducing common noise can then be an important function of mass media. Another limitation of these mechanisms is that they depend on the law of large numbers and thus these models may not be the proper description for smaller electorates (on the sub-national level, for example). As a result, information provision by mass media remains important in a large number of scenarios where voters receive some form of private signals.

\section{Conclusion}

The media and especially newspapers have been praised as the "last bastion against political corruption,"18 or the "principal bulwark" against "casual endemic civic corruption" and "[...] self dealing". ${ }^{19}$ But in order to provide readers with the necessary information to hold elected officials accountable, "the press must also have economic incentives to cover politics" (Snyder and Strömberg, 2010). We have described a plausible explanation for why voters can have a substantial willingness to pay for accountability information out of a purely instrumental motive. Our model therefore offers a more optimistic perspective on instrumental demand for information than previous research which is based on the Downsian paradigm of "rational ignorance".

Our model shows that the provision of accountability journalism can be understood as a game of the private provision of a pure public good via commercial media. This public good perspective suggests that it should be interesting to see whether key findings from the literature on the private provision of public goods also apply to information provision. For example, newspapers often make an effort to remind their readers of the watchdog role they play. Since stressing collective benefits has been shown to increase contributions in public goods experiments (Cookson, 2000), this may increase the willingness to pay for information and therefore accountability - although the newspaper may simply aim at increasing revenue. In addition, contributions to political information may depend on specific characteristics of the media outlet that provides the information. If, for instance, voters perceive non-profits in a more favorable light than profit-maximizing news platforms and this increases

\footnotetext{
${ }^{17}$ Noise terms are independent of each other and also of $g$.

${ }^{18}$ See http://www. theguardian.com/media/2009/mar/27/david-simon-wire-newspapers.

${ }^{19}$ Clay Shirky, in a talk on "Internet Issues facing Newspapers" at Harvard's Berkman Center for Internet and Society, September 22, 2009.
} 
warm glow from contributing to the public good, then the chosen legal structure of a news organization can have implications for the accountability of elected officials. Contributing in public goods settings has also been found to be facilitated by knowing the other individuals in the group, communicating with them, and especially by knowing that the others do in fact contribute (Fischbacher et al., 2001; Keser and Van Winden, 2000; Shang and Croson, 2009). If these factors, and as a result, reciprocity or conditional cooperation are more pronounced in smaller communities, this can translate into a more informed electorate.

The public good perspective introduced in this paper complements the research which deals with information and voting. It has been shown in this literature that voting and information acquisition result from a complex constellation of social and psychological factors, and this suggests interesting avenues for future research. For example, the decision to participate in elections may be affected by an overestimation of the importance of one's own vote (Riker and Ordeshook, 1968; Duffy and Tavits, 2008). If individuals are instrumentally motivated, this should also influence their demand for information. Similarly, a desire to signal to fellow citizens that one is a "good" citizen may not only drive the decision to vote (as in Funk, 2010; Aytimur et al., 2014; DellaVigna et al., 2014), but also the decision to acquire costly information. Further, it would be instructive to augment the civic duty approach in (as in Feddersen and Sandroni, 2006) with mass media, and study interactions with the public good motive we describe.

\section{Appendix}

\subsection{Proof of Lemma 3.}

It follows from Lemma 2 that $e^{*}(x)=\frac{1}{\sqrt{2 \pi}} \cdot \sqrt{\frac{\tau_{\theta} \cdot x}{\tau_{\theta}+x}} \cdot R$. A quick way to show that $E\left[E\left(\theta^{v^{*}} \mid s, x\right)\right]=$ $\sqrt{\frac{x}{\tau_{\theta}\left(\tau_{\theta}+x\right)}} \cdot \varphi(0)+\bar{\theta}$ is to substract the constant $\bar{\theta}=E\left(\theta^{I}\right)$ from $E\left[E\left(\theta^{v^{*}} \mid s, x\right)\right]$. Then we have

$$
\begin{aligned}
E\left[E\left(\theta^{v^{*}} \mid s, x\right)\right]-E\left(\theta^{I}\right) & =E\left[E\left(\theta^{v^{*}} \mid s, x\right)\right]-E\left[E\left(\theta^{I} \mid s, x\right)\right] \\
& =E\left[E\left(\theta^{v^{*}} \mid s, x\right)-E\left(\theta^{I} \mid s, x\right)\right]
\end{aligned}
$$

where $E\left(\theta^{I}\right)=E\left[E\left(\theta^{I} \mid s, x\right)\right]$ follows from the law of iterated expectation.

We define $\alpha:=E\left[\theta^{I} \mid s\right]-\bar{\theta}$. The voters elect the incumbent if $\alpha \geq 0$ and the challenger if $\alpha<0$. For the voters, prior to reading the newspaper, $\alpha$ is a normal random variable with mean zero and 
precision $\frac{\tau_{\theta}\left(\tau_{\theta}+x\right)}{x}$. Given the equilibrium voting decision it follows that

$$
\begin{aligned}
E\left(\theta^{v^{*}} \mid s, x\right)-E\left(\theta^{I} \mid s, x\right) & = \begin{cases}E\left(\theta^{I} \mid s, x\right)-E\left(\theta^{I} \mid s, x\right) & \text { for } \alpha \geq 0 \\
E\left(\theta^{C}\right)-E\left(\theta^{I} \mid s, x\right) & \text { for } \alpha<0\end{cases} \\
& = \begin{cases}0 & \text { for } \alpha \geq 0 \\
-\alpha & \text { for } \alpha<0 .\end{cases}
\end{aligned}
$$

It follows from calculus (see also DeGroot 1970: 247-248) that

$$
\int_{-\infty}^{0}-\alpha d F(\alpha)=\sqrt{\frac{x}{\tau_{\theta}\left(\tau_{\theta}+x\right)}} \cdot \varphi(0) .
$$

Re-adding the constant $\bar{\theta}$ we obtain that $E\left[E\left(\theta^{v^{*}} \mid s, x\right)\right]=\sqrt{\frac{x}{\tau_{\theta}\left(\tau_{\theta}+x\right)}} \cdot \varphi(0)+\bar{\theta}$. Substituting for the respective terms in equation (9) and subtracting $u(x=0)=2 \cdot \bar{\theta}$ yields $f(x)=\varphi(0) \cdot\left(R+\frac{1}{\tau_{\theta}}\right) \cdot \sqrt{\frac{\tau_{\theta} \cdot x}{\tau_{\theta}+x}}$.

\section{Concavity of $f(x)$.}

The first and second derivatives are

$$
f^{\prime}(x)=\frac{1}{2} \varphi(0)\left(R+\frac{1}{\tau_{\theta}}\right) \cdot \frac{\tau_{\theta}^{3 / 2}}{\left(\tau_{\theta}+x\right)^{3 / 2} x^{1 / 2}}>0
$$

and

$$
f^{\prime \prime}(x)=-\frac{1}{4} \varphi(0)\left(R+\frac{1}{\tau_{\theta}}\right) \cdot \frac{\tau_{\theta}^{3 / 2}\left(\tau_{\theta}+4 x\right)}{\left(\tau_{\theta}+x\right)^{5 / 2} x^{3 / 2}}<0 .
$$

Thus, $f(x)$ is a strictly concave function in $x$.

The slope of $f(x)$ at the origin.

We are interested in the limit value $\lim _{x \rightarrow 0} f^{\prime}(x)$. To determine the limit value it is sufficient to inspect

$$
\lim _{x \rightarrow 0} \frac{1}{\left(\tau_{\theta}+x\right)^{3 / 2} x^{1 / 2}}=\lim _{x \rightarrow 0} \frac{1}{\left(\tau_{\theta} x^{1 / 3}+x^{4 / 3}\right)^{3 / 2}}=\infty
$$

and thus $\lim _{x \rightarrow 0} f^{\prime}(x)=\infty$.

\section{References}

Aidt, T. S. (2000). Economic voting and information. Electoral Studies 19(2), 349-362. 
Alesina, A. and G. Tabellini (2007). Bureaucrats or politicians? Part I: A single policy task. The American Economic Review 97(1), 169-179.

Ashworth, S. (2005). Reputational dynamics and political careers. Journal of Law, Economics, and Organization 21(2), 441-466.

Ashworth, S. (2012). Electoral accountability: recent theoretical and empirical work. Annual Review of Political Science 15, 183-201.

Austen-Smith, D. and J. S. Banks (1996). Information aggregation, rationality, and the condorcet jury theorem. American Political Science Review 90(01), 34-45.

Aytimur, R. E., A. Boukouras, and R. Schwager (2014). Voting as a signaling device. Economic Theory 55(3), 753-777.

Aytimur, R. E. and C. Bruns (2015). On ignorant voters and busy politicians. Technical report, Discussion Papers, Center for European Governance and Economic Development Research.

Baron, D. P. (2006). Persistent media bias. Journal of Public Economics 90(1), 1-36.

Battaglini, M., R. B. Morton, and T. R. Palfrey (2010). The swing voter's curse in the laboratory. The Review of Economic Studies 77(1), 61-89.

Bernhardt, D., S. Krasa, and M. Polborn (2008). Political polarization and the electoral effects of media bias. Journal of Public Economics 92(5), 1092-1104.

Besley, T. and R. Burgess (2002). The political economy of government responsiveness: Theory and evidence from india. The Quarterly Journal of Economics 117(4), 1415-1451.

Besley, T. and M. Ghatak (2007). Retailing public goods: The economics of corporate social responsibility. Journal of public Economics 91(9), 1645-1663.

Besley, T. and A. Prat (2006). Handcuffs for the grabbing hand? the role of the media in political accountability. American Economic Review 96(3), 720-736.

Bowles, N., J. T. Hamilton, and D. Levy (2013). Transparency in politics and the media: accountability and open government. IB Tauris.

Bruns, C. (2013). Elections and market provision of information. CESifo Working Paper No. 4091.

Bruns, C. and O. Himmler (2011). Newspaper circulation and local government efficiency. The Scandinavian Journal of Economics 113(2), 470-492.

Bruns, C. and O. Himmler (2014). A theory of political accountability and journalism. MPRA Paper 59286, University Library of Munich, Germany. 
Carlyle, T. ([1841] 1993). On heroes, hero-worship, and the heroic in history, Volume 1. Univ of California Press.

Chan, J. and W. Suen (2008). A spatial theory of news consumption and electoral competition. The Review of Economic Studies 75(3), 699-728.

Cookson, R. (2000). Framing effects in public goods experiments. Experimental Economics 3(1), $55-79$.

Culbertson, H. M. and G. H. Stempel (1986). How media use and reliance affect knowledge level. Communication Research 13(4), 579-602.

de Waal, E. and K. Schoenbach (2008). Presentation style and beyond: How print newspapers and online news expand awareness of public affairs issues. Mass Communication 83 Society 11(2), $161-176$.

DeGroot, M. H. (1970). Optimal statistical decisions. New York: McGraw-Hill.

DellaVigna, S., J. A. List, U. Malmendier, and G. Rao (2014, January). Voting to Tell Others. NBER Working Papers 19832, National Bureau of Economic Research, Inc.

Diamond, P. and H. Vartiainen (2012). Behavioral economics and its applications. Princeton University Press.

Downie, L. and R. G. Kaiser (2007). The news about the news: American journalism in peril. Vintage.

Downie, L. and M. Schudson (2009). The reconstruction of american journalism. Columbia Journalism Review 19, 2009.

Downs, A. (1957). An Economic Theory of Democracy. New York: HarperCollins Publishers.

Drago, F., T. Nannicini, and F. Sobbrio (2014). Meet the press: how voters and politicians respond to newspaper entry and exit. American Economic Journal: Applied Economics 6(3), 159-188.

Duffy, J. and M. Tavits (2008). Beliefs and voting decisions: A test of the pivotal voter model. American Journal of Political Science 52(3), 603-618.

Feddersen, T. and W. Pesendorfer (1997). Voting behavior and information aggregation in elections with private information. Econometrica: Journal of the Econometric Society, 1029-1058.

Feddersen, T. and A. Sandroni (2006). Ethical voters and costly information acquisition. Quarterly Journal of Political Science 1(3), 287-311.

Feddersen, T. J. and W. Pesendorfer (1996). The swing voter's curse. The American Economic Review, $408-424$. 
Fischbacher, U., S. Gächter, and E. Fehr (2001). Are people conditionally cooperative? evidence from a public goods experiment. Economics Letters 71(3), 397-404.

Funk, P. (2010). Social Incentives and Voter Turnout: Evidence from the Swiss Mail Ballot System. Journal of the European Economic Association 8(5), 1077-1103.

Gehlbach, S. (2007). Electoral institutions and the national provision of local public goods. Quarterly Journal of Political Science 2(1), 5-25.

Gentzkow, M. (2014). Trading dollars for dollars: The price of attention online and offline. The American Economic Review 104 (5), 481-488.

Gentzkow, M. and J. M. Shapiro (2006). Media bias and reputation. Journal of Political Economy $114(2)$.

Gentzkow, M. and J. M. Shapiro (2008). Competition and truth in the market for news. The Journal of Economic Perspectives, 133-154.

Gentzkow, M., J. M. Shapiro, and D. F. Stone (2014). Media bias in the marketplace: Theory. Technical report, National Bureau of Economic Research.

Glazer, A. (2014). The Profit-maximizing Non-profit. Working Papers 131404, University of CaliforniaIrvine, Department of Economics.

Graber, D. A. (1988). Processing the news : how people tame the information tide / Doris A. Graber (2nd ed. ed.). Longman New York.

Hamilton, J. T. (2009). Subsidizing the watchdog: what would it cost to support investigative journalism at a large metropolitan daily newspaper. Duke Conference on Nonprofit Media.

Hamilton, J. T. (forthcoming). Measuring spillovers in markets for local public affairs coverage. In K. Kenski and K. H. Jamieson (Eds.), The Oxford Handbook of Political Communication. Oxford University Press.

Keser, C. and F. Van Winden (2000). Conditional cooperation and voluntary contributions to public goods. The Scandinavian Journal of Economics 102(1), 23-39.

Krugman, H. E. and E. L. Hartley (1970). Passive learning from television. Public Opinion Quarterly $34(2), 184-190$.

Larcinese, V. (2007). The instrumental voter goes to the newsagent demand for information, marginality and the media. Journal of Theoretical Politics 19(3), 249-276.

Martinelli, C. (2006). Would rational voters acquire costly information? Journal of Economic Theory 129(1), 225-251. 
Maskin, E. and J. Tirole (2004). The politician and the judge: Accountability in government. American Economic Review, 1034-1054.

McChesney, R. and J. Nichols (2011). The death and life of American journalism: The media revolution that will begin the world again. Nation Books.

Mondak, J. J. (1995). Media exposure and political discussion in us elections. The Journal of Politics 57(01), 62-85.

Mullainathan, S. and A. Shleifer (2005). The market for news. American Economic Review, 1031-1053.

Oliver, J. E., S. E. Ha, and Z. Callen (2012). Local elections and the politics of small-scale democracy. Princeton University Press.

Oliveros, S. (2013). Abstention, ideology and information acquisition. Journal of Economic Theory 148(3), 871-902.

Palfrey, T. R. and H. Rosenthal (1983). A strategic calculus of voting. Public Choice 41(1), 7-53.

Persson, T. and G. E. Tabellini (2002). Political economics: explaining economic policy. MIT press.

Pew Research Center (2010). How news happens. retrieved 09/13/2015 from http://www.journalism.org/2010/01/11/how-news-happens/.

Pew Research Center (2013). Amid criticism, support for media's "watchdog" role stands out. retrieved 08/14/2014 from http://www.people-press.org/2013/08/08/amid-criticism-support-formedias-watchdog-role-stands-out/.

Pew Research Center (2015). State of the news media 2015.

Piolatto, A. and F. Schuett (2015). Media competition and electoral politics. Journal of Public Economics, - .

Prat, A. and D. Strömberg (2013). The political economy of mass media. advances in economics and econometrics.

Pratt, J. W., H. Raiffa, and R. Schlaifer (1995). Introduction to statistical decision theory. MIT press.

Reinikka, R. and J. Svensson (2005). Fighting corruption to improve schooling: Evidence from a newspaper campaign in Uganda. Journal of the European Economic Association 3(2-3), 259-267.

Revelli, F. (2008). Performance competition in local media markets. Journal of Public Economics 92(7), $1585-1594$.

Riker, W. H. and P. C. Ordeshook (1968). A theory of the calculus of voting. American political science review 62 (01), 25-42. 
Schönbach, K., E. de Waal, and E. Lauf (2005). Research note: Online and print newspapers their impact on the extent of the perceived public agenda. European Journal of Communication 20(2), $245-258$.

Shang, J. and R. Croson (2009). A field experiment in charitable contribution: The impact of social information on the voluntary provision of public goods. The Economic Journal 119(540), 1422-1439.

Shapiro, C. and H. R. Varian (2013). Information rules: a strategic guide to the network economy. Harvard Business Press.

Shi, M. and J. Svensson (2006). Political budget cycles: Do they differ across countries and why? Journal of public economics 90(8), 1367-1389.

Snyder, J. M. and D. Strömberg (2010). Press Coverage and Political Accountability. Journal of Political Economy 118(2), 355-408.

Strömberg, D. (2001). Mass media and public policy. European Economic Review 45(4), 652-663.

Strömberg, D. (2004a). Mass media competition, political competition, and public policy. The Review of Economic Studies 71 (1), 265-284.

Strömberg, D. (2004b). Radio's impact on public spending. The Quarterly Journal of Economics, 189-221.

Svaleryd, H. and J. Vlachos (2009). Political rents in a non-corrupt democracy. Journal of Public Economics 93(3), 355-372.

Tewksbury, D., A. J. Weaver, B. D. Maddex, et al. (2001). Accidentally informed: Incidental news exposure on the world wide web. Journalism \&3 Mass Communication Quarterly 78(3), 533-554.

Vogel, H. L. (2010). Entertainment Industry Economics: A Guide for Financial Analysis. Cambridge University Press.

Waldman, S. (2011). Information needs of communities: The changing media landscape in a broadband age. DIANE Publishing.

Zukin, C. and R. Snyder (1984). Passive learning: When the media environment is the message. Public Opinion Quarterly 48(3), 629-638. 